\title{
1. Conceptualizing Causes for Lack of Recognition: Capacities, Costs and Understanding
}

\section{by Heikki Ikäheimo}

In contemporary Hegel-influenced philosophy recognition is mostly thought of as a good thing. Some see it as a pre-condition of positive, individual or collective self-conceptions or -identities, others even as ontologically foundational for the human life-form and thus as something without which we could not exist as the kinds of beings we are at all. ${ }^{2}$ But if recognition is indeed such an important and good thing, and if it is in principle something humans can give each other, why is there so often a lack of it? Why is it the case that people so often fail to give others recognition, at least adequately? There are several candidates for an explanation. First, it may be that recognition - the giving or receiving of it or both-requires capacities or skills that are not always available. Secondly, it may be that recognition, even though (all things considered) good, involves costs, which leads to reluctance to grant it. Thirdly, and relatedly, even if recognition is objectively good for the individuals or groups involved, fathoming this, or being able to experience its goodness, especially against experienced costs that it may incur, may nevertheless require intellectual capacities or understanding that individuals do not necessarily possess.

Hegel's famous story of the master and bondsman illustrates each of the three candidates. ${ }^{3}$ Firstly, starting as primitive desiring animals, Hegel's subjects seem at first unequipped with the capacity to recognize others as fully independent other subjects irreducible to one's own solipsistic perspective. But secondly, aspects of Hegel's story also suggest that lack of recognition between the subjects is not due to incapacity, but rather reluctance. In short, from their perspectives it seems that by recognizing the other one will lose something important, namely one's absolute independence or freedom from determination by the other. The third line of thought resonates with Hegel's distinction between the perspective of the combatants and the perspective of us philosophical observers: we know that what the combatants aspire to and are not willing to give up by granting recognition to each other is in fact an illusion and that by pursuing it they are in fact not acting in their own best interest. Hegel famously has two points to make here. Firstly, it turns out that the unyielding and therefore apparently independent master in fact remains dependent on the slave's 
recognition and work - which is only an illustration of the more general fact that freedom in the abstract sense of independence from other humans is for humans an impossibility. Secondly, the master in fact also remains more dependent on his own immediate natural needs and urges than the bondsman, since gaining reflective distance to and control over them only comes about through recognizing the freedom or independence of others and thereby acknowledging external constraints on oneself. All in all, though we philosophers understand that recognition is actually good for the recognizer, the protagonists of Hegel's story are originally incapable of fathoming this - which is why they are so reluctant to recognize one another.

Each of the three explanations can also be easily formulated in developmental psychological terms. ${ }^{4}$ Firstly, it takes time for the human infant to develop the capacity to fully recognize other persons-most relevantly the mother or caregiver - as independent from its own practical perspective determined by its immediate needs. But secondly, as the independence of the others implies the uncertainty of their catering for one's vital needs, the infant has in fact good reasons to be wary of it, and though it is incapable of reflecting on these reasons, it is instinctively reluctant to accept the caregivers' independence. Thirdly and finally, the psychologist and those versed in psychological thought know of course that however frightening it may be for the infant, maturation and thus the capacity to lead a life as a full-fledged adult human being essentially depends on recognizing others in their relative independence from oneself as free persons and thus accepting one's relative dependence on their independent needs and will. Incapacity, reluctance and lack of reflective understanding of one's situation and wider interests are clearly closely intertwined factors, and each of them has to be overcome to reach full adulthood in recognition of the independence of others and thus with a concrete, affective and epistemic acknowledgement of oneself as one among many. As it is often said, persons exist in plural, and thus to fully grasp oneself as a person-and since for persons their self-comprehension is partly constitutive of their being, to fully be a (psychological) person-such an acknowledgement is essential. An inadequacy or lack of such acknowledgement in adults is thus something we may call a pathology of (psychological) personhood. ${ }^{5}$

These are familiar and easily understandable ideas, and they already take us some way towards understanding why recognition is so often not forthcoming, even though in principle it is good for humans - and not only for the recognizees but also for the recognizers. Yet they only take us so far. They have at least two kinds of limitations. Firstly, they assume an idealized dyadic setting with only two subjects relating to each other, and abstract from the world of other humans or of various kinds of 'thirds' that always 
mediate particular interhuman relations. It may be that lack of recognition between $A$ and $B$ is due to the influence of $C$, whether $C$ is an individual, a collective, or norms, values or representations prevailing in the social environment. Due to A's relation to $\mathrm{C}$, it may be in fact advantageous (whether the rewards are overt or unconscious) for her to deny recognition from B. A second problem is the simplicity of the concept of recognition that these familiar ideas, as I have presented them, assume. On this concept, to recognize someone is in some way to accept or acknowledge her freedom in the sense of independence from oneself. Hegel's own language sometimes suggests such a concept, and this is also how recognition is often understood in psychologically or psychoanalytically informed writing. But in recent years, philosophers and theorists have started thinking of the concept of recognition in a more differentiated way, ${ }^{6}$ and thus the question remains how to explain lack of recognition in light of the more differentiated concept or concepts that we now have at our disposal, a concept that should in principle give us a more nuanced understanding of the complex of phenomena at issue in discourses on recognition.

In what follows, I will try to clarify the question that I started with in terms of the most differentiated analysis of the concept of recognition that I can currently think of. Freedom will turn out to be a central issue to do with recognition also on this account, though on a concept more elaborate than that of freedom as independence from others. I will mostly work in terms of the dyadic model, but will return to the issue of the 'third' towards the end.

\section{Recognition, an Analysis}

One of the main moves in Axel Honneth's influential early work on this theme in his monograph The Struggle for Recognition is the differentiation of the conceptual terrain of recognition into three dimensions, as it were, corresponding to the three forms of recognition of love, respect and esteem. ${ }^{7}$ This is an important distinction and widely understood nowadays to be necessary for a comprehensive understanding of the complex of phenomena at issue in theoretical and everyday discourses on the theme. Yet it is only one among several important distinctions without which we are bound to speak and think confusedly of this complex. Let me go through what I think are some of the most important distinctions to make.

\section{Vertical Versus Horizontal Recognition}

The first distinction that we need to make is between 'vertical' and 'horizontal' senses of recognition. By vertical recognition I mean recognition 
between persons and norms or institutions. Norms exist as norms if and only if they are 'recognized' by those whose life they govern, and the same is true of institutions thought of as systems of norms. ${ }^{8}$ In addition to this 'upwards'direction of vertical recognition, we often also talk of a 'downwards'-direction of institutions such as the state 'recognizing' persons in the sense of granting them rights or respecting their rights. ${ }^{9}$ By the horizontal sense of recognition I mean recognition between persons. One could think that this distinction between the vertical and horizontal senses of the term turns on a contingent homonymy of completely distinct phenomena, but a closer inspection shows that the phenomena are in fact closely interrelated and thus that the homonymy is by no means contingent or unmotivated. ${ }^{10}$

\section{Normatively Mediated Versus Purely Intersubjective Horizontal Recognition}

The second important distinction we need to make is between two forms of horizontal recognition: 'normatively mediated'11 and 'purely intersubjective'. What I mean by the first is recognition of someone as a bearer of entitlements or rights stipulated by norms. These may be institutionalized norms and thus institutional rights granted or recognized 'vertically downwards' by the state or other relevant authority, or they may be more informal norms and thus informal entitlements or rights in force in interaction. Having a right or entitlement means that relevant others ought to treat one in ways that accord with the right or entitlement, and this is what it means for them to 'recognize' one in the normatively mediated sense. In other words, recognition is 'mediated' by the norm that stipulates the right or entitlement in question in the sense that being a bearer of the right or entitlement obligates others to recognize one as such. It is easy to see that recognizing norms (vertically upwards) and recognizing persons (horizontally) in the normatively mediated sense are very closely connected.

In contrast to normatively mediated recognition, purely intersubjective recognition is not mediated in this sense, or in other words it is not a required or obligatory response to a given norm, or to a person as a bearer of rights or entitlements stipulated by the norm. Rather, it is a response to a person independently of her rights or entitlements. Another way to put this is that whereas normatively mediated recognition is a response to a person as a bearer of a normative or deontic status or role, ${ }^{12}$ purely intersubjective recognition is a response to her irrespectively of such statuses or roles, or, to offer a short expression, as an individual. (This latter, tentative formulation needs to be specified later however, after we have introduced a distinction between what I call the 'conditional' and the 
'unconditional' mode of purely intersubjective recognition.)

In debates on recognition, the normatively mediated and purely intersubjective senses of the term are very often confused, and this may be partly due to the ambivalence of the word 'respect' between normatively mediated and purely intersubjective use. We talk of both respecting someone's rights or in other words her as a rights-bearer, and of respecting someone as an individual whose validity-claims demand serious consideration, or in other words as commanding authority (possibly including authority on her rights or on those of others) ${ }^{13}$ In what follows I will reserve the term 'respect' for the latter, purely intersubjective use, and denote the former, normatively mediated sense with 'respect"' or 'recognition*'.

The Axiological, Deontological and Contributive Dimensions of Horizontal Recognition

I already mentioned the important distinction between the three dimensions of recognition, originally introduced by Axel Honneth. The distinction is however in need of further clarification in that Honneth's own discussion of 'respect' as one of the three forms of recognition does not clearly enough distinguish between vertical downwards recognition (or granting rights) and horizontal recognition, nor between the institutionally mediated and the purely intersubjective senses of horizontal recognition, or between respect* and respect as I call them. ${ }^{14}$ We can be clearer by saying that there are three 'dimensions' of horizontal recognition, one of which has two 'layers', the institutionally mediated (i.e. respect*) and the purely intersubjective (i.e. respect), whereas the two other dimensions only consist of purely intersubjective phenomena. I will call the three dimensions of horizontal recognition the deontological, the axiological, and the contributive. For reasons that will become clear shortly, we also need to grasp the three forms of purely intersubjective recognition first at a more general level than Honneth does with his distinction between love, respect and esteem. At this more general level, purely intersubjective recognition is on the axiological dimension concern for the happiness or well-being of the other, on the deontological dimension taking the other as having, or sharing with one, authority on the norms or terms of shared life with her, and on the contributive dimension valuing her as contributor to something one values, or as a bearer of capacities for such contributions. Only after differentiating purely intersubjective horizontal recognition into the three dimensions first at this higher level of abstraction should we start speaking about more specific phenomena such as love or respect. However, in order to do this, 
there is one more distinction that needs to be made, namely a distinction between what I call the two 'modes' of purely intersubjective recognition.

\section{The Conditional and the Unconditional Modes of Purely Intersubjective Horizontal Recognition}

On each of the three dimensions, purely intersubjective recognition has a 'conditional' and an 'unconditional' mode or variant. Considering the fact that recognition is usually thought to be a morally or ethically charged concept, as soon as one introduces this distinction it seems rather striking that it has so far been practically absent from the philosophical and theoretical debates on recognition. On the axiological dimension, the conditional mode of recognition is prudential or instrumental concern for the well-being of the other, or in other words concern for her that is conditional on one's concern for one's own well-being or interests: I care about the happiness or well-being of the other insofar as it serves my own happiness, well-being or ends (including the happiness or well-being of some third person or persons I care about). In contrast, the unconditional mode of purely intersubjective recognition on the axiological dimension is unconditional concern for the happiness or well-being of the other, or in other words concern for it 'not for my or someone else's sake, but for hers'. Love is the word usually used for this unconditional mode of concern for the other, but not for the conditional mode.

On the deontological dimension, the conditional mode of purely intersubjective recognition is taking the other as having, or 'attributing to her', authority on one out of prudential considerations, or in other words out of fear or calculation of utility. That is to say that I accept the other's authority on the norms or terms of our co-existence and thus on myself, whether in general or with regard to particular issues, because and to the extent that I fear the consequences of not doing so, or because and to the extent that I estimate it as more useful or advantageous for myself than not doing so. Hegel's bondsman 'recognizes' his master or accepts the latter's authority in the relationship since he fears for the consequences of not doing so. And one can argue that the master must in fact accept the bondsman as having some minimal, technical authority in applying the master's commands in particular cases and thus determining their exact content in practice, since not doing so would mean that his commands could not be executed at all. The unconditional mode of purely intersubjective recognition in the deontological dimension is in contrast taking the other as having, or attributing her, authority on one 'full stop', unconditioned by prudential considerations. Having such an attitude towards another means, for example, that one may feel ashamed in front of him. Respect is the word 
usually used for this unconditional mode of taking the other as authority. It is of course sometimes also used more loosely, covering also the conditional mode, but then its meaning isn't clearly distinct from 'fear' or other prudential stances towards its object, whereas in the central unconditional sense it is.

On the contributive dimension, the conditional mode of purely intersubjective recognition is valuing someone instrumentally for her contributions to what one values, or for capacities for such contributions. Hegel's master values the bondsman as useful for his ends, and if we accept this as a form of recognition then we must say that in this sense too, the master does actually have recognition for the bondsman. But here we are clearly at an important juncture regarding how to conceptualize the complex of phenomena designated by the term 'recognition'. Do we, or do we not want to say that instrumental valuing is a form of recognition? Again, considering the fact that recognition is usually thought to be a morally charged concept, and considering that instrumentalization, or at least 'mere instrumentalization', is usually thought to be morally at least problematicthink of the second formulation of Kant's categorical imperative-it is surprising that very little attention has been paid to this question in philosophical literature on recognition. ${ }^{15}$ My suggestion is not to stipulate that instrumental valuing is not a form of recognition at all, but rather to accept that it is recognition of sorts, namely the 'conditional mode' of purely intersubjective recognition on the contributive dimension. ${ }^{16}$ It is contrasted with the unconditional mode or way of valuing or appreciating someone as a contributor to what one values. But is there actually a form or mode of valuing or appreciating someone as a contributor to something one values that is not instrumental valuing, and if so what is it? There clearly is - namely gratitude. The analogy of the distinction between the conditional and unconditional on the contributive dimension and the same distinction on the axiological and deontological dimensions is not perfect since also gratitude is in some sense conditional on one's own interests. Yet, there are subtle but important differences between what I call the conditional and unconditional mode also on the contributive dimension. Whereas one only instrumentally values something that (one believes) actually contributes (or may contribute) to what one values, it is entirely appropriate to be grateful for someone for mere failed attempts to contribute to what one values. In other words, whereas in instrumental valuing the object is actual performance (or at least a real possibility of actual performance) or its results that contribute to what one values, and the intentions of the agent are only of secondary importance, in gratitude the object is the agent's intentions, and successful performance that has (or one believes to have) beneficial consequences to one is not required for gratitude to be appropriate. The exact content of the intentions 
are of utmost importance for the appropriateness of gratitude. Firstly, it is not enough that the other intended to do something that would in fact have contributed to what one values. For gratitude to be appropriate, the agent would also have had to intend to contribute to what one values. ${ }^{17}$ And secondly, she would have had to intend this at least in part 'for the sake of' the beneficiary, or in other words with genuinely altruistic motivation or love in the above defined sense.

Central for the analogy of the two modes of purely intersubjective recognition on the three dimensions is that on all three dimensions in the unconditional mode 'what ultimately counts' is the perspective or intentionality of the other, whereas in the conditional mode what ultimately counts is one's own perspective. Whether or how the perspective of the other counts, is in the conditional mode dependent on its prudential or instrumental significance for one. ${ }^{18}$ One could therefore also rename the distinction between the conditional and the unconditional modes as a distinction between the 'egocentric' and the 'allocentric' mode. A third alternative terminology for the same contrast between the two modes would be 'not-genuinely personifying' versus 'genuinely personifying', the rationale for this being that only in the unconditional/allocentric/genuinely personifying mode does the other count for me as a genuinely other person irreducible to my own practical perspective. Because of this we need to specify also the claim I made earlier that, in contrast to normatively mediated recognition where the object is taken as a bearer of a role consisting of deontic powers, in purely intersubjective recognition the object is taken as an individual. It is namely only in the unconditional mode of purely intersubjective recognition that the recognizee is seen or taken as an individual in the strong sense of irreducible to functional significance in the recognizer's self-interested perspective, and thus as an irreducible and irreplaceable other person.

\section{Lack of Recognition Revisited}

What more can we now say to respond to the question concerning the existence of lack of recognition than what was already said at the beginning, by reference to the three ideas of incapacity, costs and reluctance, and understanding? Let us see where we can get by utilizing these ideas again, this time putting to work the more differentiated understanding of recognition that we are now equipped with. At this point, it is necessary also to make explicit certain other issues that are at the background of the Hegelian account of recognition, as well as arguably of any plausible developmental psychological account, namely issues concerning the general 
structure of life with the human form. As we shall see, this will also turn out to have consequences for the concept of freedom. For lack of space, I will limit my discussion from here on to the deontological dimension, though I believe analogous points can be made of the two other dimensions. On the deontological dimension we can note that one of the essential features of the human life-form distinguishing it from simpler animal life-forms is that it is governed by social norms authorized by humans themselves. This is to say that collectively speaking humans are autonomous beings - whether or not particular individuals or collectives have a well-articulated understanding of this, in whatever way authority happens to be distributed between individuals in a particular community or society, or whether or not the norms of the community are good or rational on some relevant conception. This means that to live a life with this form, an individual must recognize 'vertically upwards' some norms as governing her life, and it also means that she must recognize some others horizontally both in the normatively mediated sense as bearers of the rights, duties, entitlements and responsibilities (or 'deontic powers' to borrow a term from John Searle) prescribed by the norms, and well as in the purely intersubjective sense as having or sharing authority on those norms. ${ }^{19}$ Hence, freedom in the sense of general independence from other humans and thereby shared norms as constraints to one's actions is for humans, as humans (or as 'human persons' to speak more precisely), ${ }^{20}$ an impossibility.

How does this now look from the point of view of the three candidate explanations for non-recognition? Individual capacities to submit oneself under norms and thus the authority of others clearly differ, some of the differences being innate (think of psychopathy), others due to differences in early interaction with the caregiver(s) or in later stages of socialization. A more detailed examination of these differences is the task of psychology, psychoanalysis, cultural anthropology and other more empirically oriented branches of inquiry. But what we can do without leaving the philosophical armchair is to take a closer look at the connection of costs and understanding. Though freedom in the sense of independence from others or more generally from determination by anything other than oneself is self-subverting when applied to reality, ${ }^{21}$ there is another sense of freedom which is not. This is what Hegel calls 'concrete freedom' and describes with the famous formula of 'knowing oneself in otherness', by which he means overcoming the alienness or hostility of what determines one. ${ }^{22}$

The connection of these two ideas or concepts of freedom to the question I started with is that the latter is significantly more complex and thus requires more in terms of intellectual capacities or understanding than the 'abstract' concept of freedom as independence from determination. If 
determination by norms and thus by others as authorities on those norms is experienced as imprisonment or as threatening dependence on the whims of the others, and thus as being in general against one's vital interest of selfpreservation as a free being, then reluctance to grant recognition to the norms and the relevant others is perfectly consequent. In this case the reasons for recognition available for the subject can only be prudential, i.e. the costs of not yielding appearing to outweigh the costs of yielding: Hegel's bondsman yields to the authority of the master and thus his commands or norms because the alternative seems to him even worse; and an infant yields to the will of adults and to the norms of the adult world to the extent that it fears the existential consequences of not doing so even more than dependence on the adults.

In this picture, humanity is thus something to which the human animal submits himself only reluctantly, not really wanting it but having no feasible alternative. And wherever she can actually get away with it, she is prone to deny recognition from particular others as having authority on her. To stabilize social order the authority of others, or of the society, thus needs to be somehow internalized, so to say, as an internal master threatening the person as a bondsman, or else there must be a strong enough external threat of punishment, or both. This is of course a bleak picture of collective autonomy, a picture in which it is at the level of individuals actually a state of mutual bondage and heteronomy. Even if everyone were equally feared by everyone else, and recognition as fear or prudentiality would thus be fully symmetrical, this would clearly be a highly unappealing picture of human sociality and thus of being human, something bound to inspire fantasies of escaping humanity.

But is this the only way to understand what it is for humans to live distinctively human lives essentially involving collective self-governance by social norms? Hegel certainly didn't think so. We can understand his talk of concrete freedom as 'finding oneself in the other' on this deontological dimension of purely intersubjective recognition as finding oneself affirmed by the others in the sense of having authority attributed to one by them. And importantly, not finding them attributing authority to one, at least exclusively, in the conditional mode - that is, for merely prudential motives of fear or calculation of costs and utility-but at least also in the unconditional mode of respect. One way in which this is genuine freedom is that unlike the conditional mode of recognition as attribution of authority it is not dependent on the contingencies of the recognizer's prudential situation - unlike conditional attribution of authority it does not cease if one ceases to be threatening or useful in her eyes. Another way to put the same point is that as an object of respect I can find my authority on the norms or 
terms of co-existence affirmed by the recognizers in a way that fully satisfies my own claim as a rational being, and in this sense fully allows me to 'know myself in them.' What I mean is the claim that my judgements and setting of ends are to be taken seriously as having a claim for authoritativeness by the relevant others independently of their prudential considerations. I thus count fully as a person and in this sense as an irreplaceable individual in the intersubjective context in question.

Being an object of recognition as respect seems fairly unproblematically to be a good thing for beings that are constitutively bound to others with whom they share norm-governed life-an essential element of their 'concrete freedom' as autonomy. But what about being a subject of respect: in what way, if any, is it good for the recognizer to recognize others in this sense? A tempting angle is again prudential: if one does not respect others, this may make it less likely that they will respect one in turn. But note that though the respect one receives from others may indeed be influenced by one's respect for them or lack thereof, this cannot be a subjective reason for respecting others, for respect is precisely not conditional on prudential considerations. Moreover, the unconditional mode of recognition as attribution of authority, or respect, is not an attitude for which the subject can have subjective reasons of any kind. Respecting someone for a reason is a contradiction in terms, since it assumes that one holds the authority to give or withhold respect, depending on one's judgement of the balance of reasons. But respecting the other is precisely attributing authority to her on the ways in which one relates to her, authority which is not conditional on one's own judgements and thus one's own authority, but irreducible to it or co-original with it. To put this in another way: respecting someone is not to be moved by reasons, but rather by the person herself as a rational being with a claim to sharing authority, including authority on what counts as acceptable reasons for treating her in this or that way. ${ }^{23}$

This clearly also implies limitations as to the way in which an adequate understanding of the human condition - of the futility of the 'abstract' idea of freedom and of the goodness of concrete freedom as mutual respect-can contribute to making respecting others more likely. Even if a person has a theoretical understanding of these facts, it cannot provide subjective reasons for her to have respect for others, since respect cannot strictly speaking have subjective reasons. In reflecting on these matters in thought we occupy the standpoint of Hegel's philosophical "we", but in our concrete relations with each other we are in the position of "natural consciousness", and for the above explained reasons the wisdom we may have in the first role cannot directly modify the way we relate to each other in the second. In real life the capacity and propensity to have genuine respect 
for others develops, if it does, through good-enough early interaction and later stages of socialization with care-givers and other relevant others where the infant, child and adult concretely learns to trust others, and thus to lower her psychological defences and be open to the others in ways that allow her to be moved by the others as having unconditional authority on her, while at the same time expecting them to relate to her similarly, having a healthy confidence that they will do so, and the strength not to be psychologically devastated if they don't. An effective understanding of the goodness of mutual respect and the ways in which it is in a meaningful sense freedom is thus not of a theoretical but of a practical nature. It is part and parcel of the capacity, and develops, or erodes with it. ${ }^{24}$

So then what role, if any, does theoretical understanding or comprehension have in explaining a lack of recognition in human relations, and how is it related, if it is, to reluctance? To comprehend this, we need to make a little detour. Though attitudes of unconditional intersubjective recognition (and not only respect, but love and gratitude as well) are not directly responsive to reasons, they are affected by many factors, not only in the subject's particular psychological constitution, but also in the wider world, or by the various 'thirds' that I mentioned at the beginning. If genuine respect is being moved 'unconditionally' by others, then any factors that make it more or less likely that persons will encounter each other in ways in which such affection or being moved can, or is likely to happen, or in which persons can 'afford' it, are factors affecting the likelihood of recognition as respect in particular human relations. Institutional roles or functional demands in particular contexts of action or interaction may be such that individuals have little room to attend to each other in ways that would elicit in them the affect of genuine respect for one another. It may even be that the relevant norms or functional demands require the explicit denial of the perspective of one or more parties to the interaction having authority in the interaction, and thus making it the case that individuals acting in normgoverned or functional roles cannot afford to attend to the others in question in ways that would elicit in them respect for those others. The first kinds of cases can easily take place in any highly formalized bureaucratic settings. The latter kinds of cases may take place, for example, in penal institutions or practices where part of the punishment is (or is understood to be) making the inmates feel that their authority on the norms or terms of how they are being treated counts for little or nothing, and where it is thus part of the norms defining the wardens' duties, or part of prevailing understanding of what it is to do the warden's job well, that they avoid encountering the inmates in ways which are likely to elicit in them respect for the latter. Hence, so it may be thought, to do the warden's job well, one must psychically 
distance or shield oneself from the inmates. Hence for a psychologically wellfunctioning person, working as a warden involves, as it were, reluctance of a second order required by the role, which in 'successful' cases trumps the normal first order recognitive affection.

'Not affording' and the consequent second order reluctance to let oneself be moved by the affection of respect can take place also in more equal social settings. Think of an idealized capitalist market, where persons, as market actors, are required to act selfishly to satisfy the norms or functional requirements of their roles. ${ }^{25}$ To do so requires that they are only moved by each other's authority prudentially. Your judgements of me or my actions in the relation are expected to matter to me only insofar as they are relevant for my getting from you what I want, possibly including your willingness to engage in future transactions that I expect to be beneficial for me. Being moved unconditionally by you with the affect of genuine respect could impact negatively upon my efficiency as a market actor, and thus to be an ideal market agent I must shield myself, as best as I can, from being so moved. Again a second order reluctance due to demands of the 'third' of the norms and functional demands of the market-institution may trump, and in 'successful' cases will trump, the normal human response, the disposition to which is the product of good enough socialization. ${ }^{26}$

The most extreme forms of the same phenomenon are found in war, genocide and mass-murder where, to be able to act as perpetrators, those with normal human subjectivity need to be trained to suppress their normal unconditional recognitive responses, or need to be brainwashed so that these responses are bypassed in them (thus effectively making them 'abnormal'). Though people who are damaged in infancy or childhood in ways that reduce their capacity for unconditional recognition, or that make denying recognition from others desirable in their perspectives, may often be the ones best suited for engaging in warfare, mass-murder or genocide, we know all too well the efficiency of psychological manipulation and propaganda in suppressing or bypassing respect towards particular individuals or groups also in more or less normal healthy adults, leading to their capacity to participate in atrocities. A major factor in such processes of brutalization is the manipulation of the environment of mutual expectations among the potential perpetrators so that it will become increasingly costly for individuals to express and act upon their normal recognitive responses towards the victims, leading again to increasing second order reluctance. An essential element of the required 'depersonification' of the victims is this withdrawal of respect from them as having authority on the norms or terms in which they are treated in concrete intersubjective encounter. (This also illustrates the point of calling the unconditional mode of purely 
intersubjective recognition 'genuinely personifying' as I proposed above.)

To repeat the question that I posed earlier: what role, if any, does theoretical understanding or comprehension have in explaining lack of recognition in human relations? Theoretical understanding is clearly essential in designing and devising institutional conditions in which the unconditional recognitive response either has to be suppressed due to its costs for individuals, or has room to flourish in interhuman relations. Perhaps the most directly relevant issue for philosophers and social theorists in particular is the role of conceptions of freedom in guiding thinking about goodness and badness in social practices and institutional designs. Subscribing to the "abstract" concept of freedom as independence from determination by others inevitably leads to thinking of genuine respect (as well as the other forms of unconditional intersubjective recognition, love and gratitude) as threatening freedom. As I pointed out, it is this crude concept of freedom which unreflectively guides the actions of Hegel's protagonists in the master-bondsman-story, as well as those of an infant who hasn't (yet) learned that the relative independence of the mother, and thus one's relative dependence on her, is actually not a mortal threat. What natural consciousness learns in the course of Hegel's Phenomenology of Spirit, and what all of us have learned in practice if we have been lucky, is that freedom from determination by others is a destructive fantasy, and that determination by others is compatible with real freedom. Hegel's concept of "concrete freedom" is thus central for a philosophical understanding of how social relations imbued with mutual unconditional or 'genuinely personifying' recognition are the ideally free relations for norm-governed beings like us. They are what freedom means, concretely, for beings like us, with the form of life that we have. Any philosophy or social theory lacking an understanding of these ontological facts about human life will be unable to articulate the importance of creating or protecting social and institutional conditions in which unconditional intersubjective recognition and thus real freedom can flourish, and at worst they may provide support for undermining them. ${ }^{27}$

Heikki Ikäheimo (h.ikaheimo@unsw.edu.au) has a PhD from University of Jyväskylä. He did a post doc at University of Frankfurt and another one at Macquarie University. He works nowadays as Senior Lecturer and Australian Research Fellow at UNSW Australia. 


\section{Bibliography}

Benjamin, J. (1988) The Bonds of Love. Psychoanalysis, Feminism, and the Problem of Domination New York: Pantheon Books

Brandom, R. (2007) 'The Structure of Desire and Recognition: SelfConsciousness and Self-Constitution' Philosophy and Social Criticism vol. 33, no. 1, pp. 127-150

Castoriadis, C. (1986) 'First Institution of Society and Second Order Institutions' in Figures of the Thinkable (trans. D. A. Curtis) (no publication date, essay published in French in 1986), pp. 153-172. Available at http://www.notbored.org/FTPK.pdf

Hegel, G. W. F. (1978-9) Hegel's Philosophy of Subjective Spirit (trans. M. J. Petry), Dordrecht: Reidel

Honneth, A. (1995) The Struggle for Recognition. The Moral Grammar of Social Conflicts (trans. J. Anderson) Cambridge: Polity Press

Honneth, A. (2014) Freedom's Right - The Social Foundations of Democratic Life Cambridge: Polity Press

Ikäheimo, H. (2007) 'Recognizing Persons' Journal of Consciousness Studies vol. 14, no. 5-6, pp. 224-47

Ikäheimo, H. (2012) 'Globalizing Love - on the Nature and Scope of Love as a Form of Recognition' Res Publica vol. 18, pp. 11-24

Ikäheimo, H. (2014) Anerkennung Berlin: De Gruyter

Ikäheimo, H. (forthcoming) 'Ethical Perfectionism in Social Ontology - A Hegelian Alternative' in I. Testa, L. Ruggiu \& L. Cortella (eds.) I that is We, We that is I. Perspectives on Contemporary Hegel Leiden: Brill

Ikäheimo, H. \& Laitinen, A. (2007) 'Analyzing Recognition: Identification, Acknowledgement, and Recognitive Attitudes towards Persons' in B. van den Brink \& D. Owen (eds.) Recognition and Power: Axel Honneth and the Tradition of Critical Social Theory Cambridge: Cambridge University Press, pp.33-56 
Ikäheimo, H. \& Laitinen, A. (2010) 'Esteem for Contributions to the Common Good - the Role of Personifying Attitudes and Instrumental Value' in M. Seymour (ed.) The Plural States of Recognition New York: Palgrave

Searle, J. (2010) Making the Social World Oxford: Oxford University Press

Taylor, C. (1994) 'The Politics of Recognition' in A. Guttman (ed.) Multiculturalism - Examining the Politics of Recognition Princeton: Princeton University Press

\section{Endnotes}

${ }^{1}$ I thank Alison Beale, Onni Hirvonen, Eerik Lagerspetz, Arto Laitinen, Petteri Niemi and Sari Roman-Lagerspetz for helpful comments to an earlier version of the paper, and the Australian Research Council (project Social Ontology of Personhood) for funding.

${ }^{2}$ Charles Taylor (1994) is usually associated with the first view, Robert Brandom (2007) with the second.

${ }^{3}$ I have in mind here especially the 'complete story' as Hegel gives it in the Encyclopaedia of Philosophical Sciences (Hegel 1978-9), but much of what I say applies also to the non-complete story ending with the unequal relationship of the master and bondsman in the Phenomenology of Spirit.

${ }^{4}$ See especially Jessica Benjamin (1988).

5 Note that this has no automatic implications regarding juridical personhood. It is a matter for ethical and juridical deliberation what role, if any, individual psychological capacities have in determining to whom or what juridical personhood is granted. See Ikäheimo 2007.

${ }^{6}$ See Honneth (1995), Ikäheimo \& Laitinen (2007), and Ikäheimo (2014).

${ }^{7}$ See Honneth (1995).

${ }^{8}$ See John Searle on "recognition or acceptance" of institutions in Searle $(2010,8)$. We call 'recognition' of norms, values and other "normative and evaluative entities" "acknowledgement" in Ikäheimo \& Laitinen 2007.

${ }^{9}$ Since the state is not an intentional subject capable of having attitudes of 
recognition, this sense of 'recognition' is metaphoric. There are ways to analyse it in terms of human attitudes and thus to conceive it as literally a matter of recognition, but this task cannot be executed here. Thanks to Arto Laitinen for a helpful comment regarding this issue, as well as for many other detailed comments.

${ }^{10}$ On the connection between the vertical and horizontal directions of recognition, see Ikäheimo (forthcoming).

${ }^{11}$ In Ikäheimo (2014 and forthcoming) I call this 'institutionally mediated', but 'normatively mediated' may work better since I mean to cover both institutionalized norms, and norms that come about and are administered in intersubjective interaction, without being institutionalized in the sense of administered by a 'third' instance. In discourses on recognition for example Axel Honneth usually talks of institutionalized norms, whereas Robert Brandom focusses more on purely intersubjective norms. A synoptic theory of recognition needs to have both in view. The term 'normative' has of course also wider uses, but here it refers exclusively to social (whether institutionalized or non-institutionalized) norms.

${ }^{12}$ On the concept of deontic status, see Searle 2010.

13 'Authority' is here not to be understood as an institutional role, or as something that is due to such a role, say that of a judge or minister, but simply intersubjective authority that one commands in interaction with others independently of one's rights.

${ }^{14}$ See Honneth $(1975,107-121)$.

${ }^{15}$ The only exception I am aware of is Ikäheimo \& Laitinen (2010).

${ }^{16}$ This is my response to Arto Laitinen's emphasis on instrumental valuing as an important form of recognition in ibid.

${ }^{17}$ This includes also cases in which what the other intended to do actually did not contribute to what one values.

18 For example, I may indeed value instrumentally the other's loving benevolence towards me though she has failed to actually contribute positively to my good, since I may estimate that her motivation may benefit me in some other way or on some other occasion. In contrast, in gratitude 
the significance of the other's loving benevolence is in my perspective not instrumental. I thank Nick Smith for a helpful discussion on this theme.

${ }^{19}$ I abstract here from the question concerning the possibility of private rules or norms. Distinctively human life is social and thus the relevant norms are in any case social or shared.

${ }^{20}$ Throughout the text the word 'human' refers to 'human persons', i.e. to humans insofar as they are capable of leading a life with a form that is not 'merely animal'. This centrally involves governance by self-authorized norms. For more on this theme, see see Ikäheimo 2014, chapter 7.2.

${ }^{21}{ }^{1}$ Hegel's master exemplifies the consequences of the attempt to prove one's independence in this sense, declining to recognize others as bearers and authorities of deontic powers and thereby to acknowledge anything as shared or social norms genuinely binding oneself. (I am assuming here that what really binds one to norms cannot be one's own will, but that it must be the will of others who in one's perspective have authority on the norms and thus on one.) On the one hand, he in fact has to engage in norm-governed interaction with the bondsman in which he cannot avoid some amount of constraint by the latter, yet on the other hand this constraint remains so minimal that it does not fully pull the master out of the animal state of determination by immediate impulses.

\section{${ }^{22}$ See Ikäheimo 2014, chapter 4.}

${ }^{23}$ It is widely understood in philosophical treatises of love that loving as concern for someone's happiness or well-being is not being moved by reasons to love her, but by the person herself (see Ikäheimo 2012). I am arguing here that the same is true of all unconditional attitudes of purely intersubjective recognition. In a word, they are more fundamental than orientation in the space of reasons. This idea goes back, at least, to Fichte's idea of the "summons" (Aufforderung) as a pre-rational introduction to rationality (see Ikäheimo 2014, chapter 3). Thanks to Arto Laitinen and Petteri Niemi for pressing me on this issue.

${ }^{24}$ This has obvious implications regarding the overcoming of incapacity due to less than ideal socialization at the individual level: gaining theoretical understanding is unlikely to be enough. What is needed is psychotherapy through which the individual may gain or regain a lost, or undeveloped, sense of trust. 
25 Embedded in social life, real market relations are of course only approximations of the idealized setting. Equally, to the extent that market relations "colonize" (to borrow Habermas' term) social life, the latter becomes less accommodating of unconditional recognition.

${ }^{26}$ Note that this implies a so to say 'normative' notion of normality: the 'normal' is what is good for life with a certain form. Normality in this normative sense applies equally to plant, animal and human forms of life, though with quite different contents.

${ }^{27}$ Honneth 2014 is a reactualization and application of Hegel's idea of concrete freedom for contemporary conditions. It is exemplary in the way it aims to affect the general framework in which freedom is thought, so as to make it compatible with and supportive of what we all (should) know in practice: that abstract freedom is an inadequate concept of freedom. The concept of recognition plays a conspicuously minor role in this book, but that is an issue easily corrected by further work. 